\title{
A Mechanism for Land-Atmosphere Feedback Involving Planetary Wave Structures
}

(1)

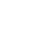

(

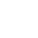

8

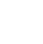

Randal D. Koster ${ }^{1}$, Yehui Chang ${ }^{1,2}$, and Siegfried D. Schubert ${ }^{1}$ 


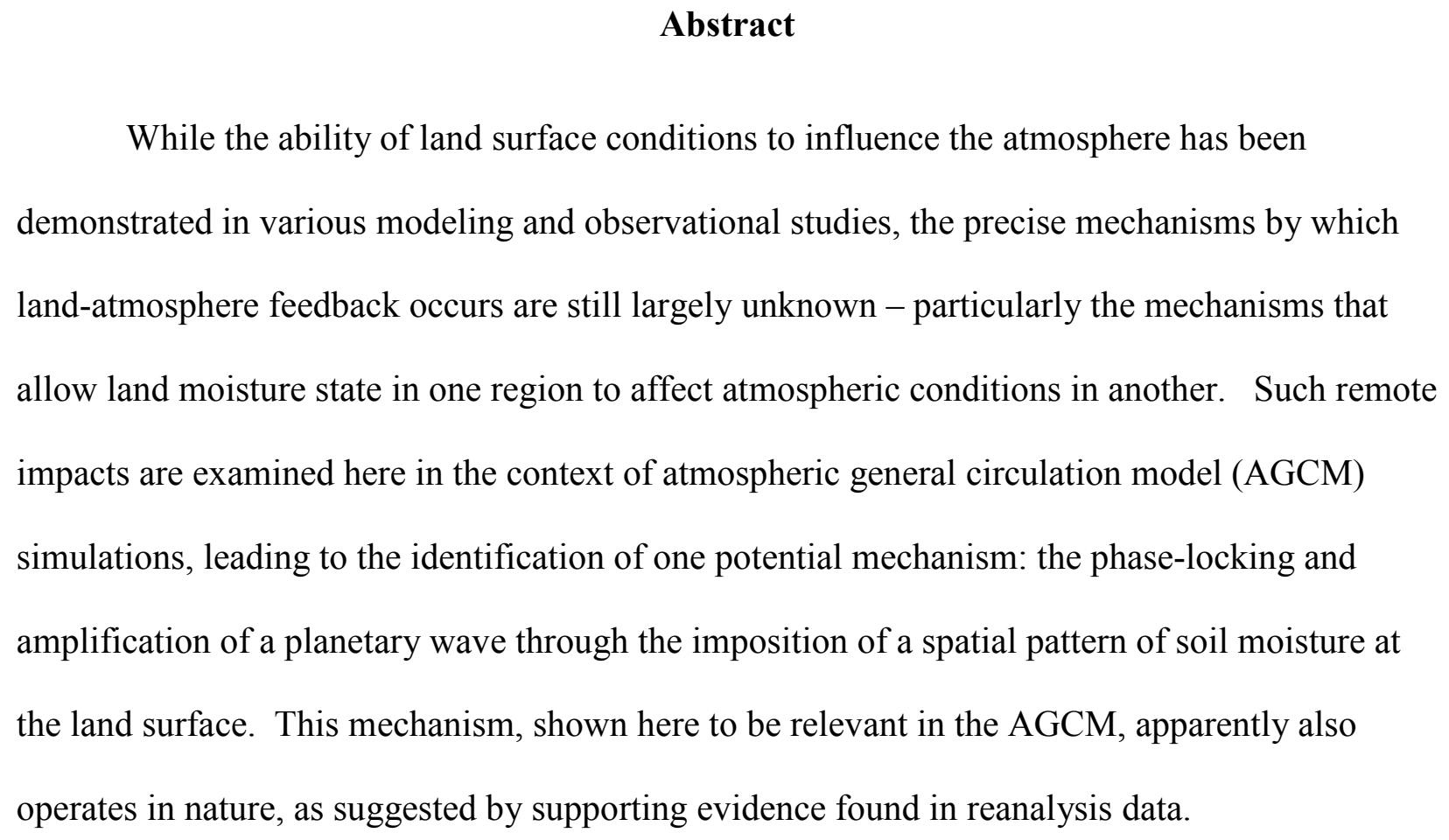




\section{Introduction}

Numerous studies with atmospheric general circulation models (AGCMs) have demonstrated the ability of soil moisture variations to affect the overlying atmosphere (e.g., Shukla and Mintz 1982, Delworth and Manabe 1989, Koster et al. 2000, Douville et al. 2001, Guo et al. 2012). Observations-based studies are also suggestive of such impacts (e.g., Betts and Ball 1995, Findell and Eltahir 1997, Koster et al. 2003, 2011, Taylor et al. 2011). The impacts are often discussed in the context of "land-atmosphere feedback" because the affected atmospheric variables (e.g., air temperature, precipitation) are often the ones that helped produce the soil moisture variations in the first place.

The impacts identified in the literature are generally at the local scale. A wetter-thanaverage soil might change the relative magnitudes of the surface turbulent fluxes, which in turn might induce changes in the overlying boundary layer, perhaps leading to conditions more conducive to moist convection (Betts et al., 1994). A higher evaporation rate from a wetter-thanaverage soil would also reduce surface temperature through evaporative cooling, which in turn could reduce the temperature of the overlying air (e.g., Seneviratne et al. 2010).

The ability of soil moisture, however, to have a remote impact on the atmosphere - an impact, for example, on air temperatures a thousand kilometers away - is still largely undetermined, addressed by only a handful of studies (e.g., van den Dool et al. 2003). Taylor et al. (2011) examine mechanisms for remote impacts at the mesoscale (tens to hundreds of kilometers). At even larger scales, the mechanisms must involve changes in the large scale circulation. How this would work is still largely unexplored. 
We examine this question here. We use an AGCM to explore one potential mechanism for remote soil moisture impacts on meteorological fields, a mechanism involving the phaselocking of a planetary wave over a specific soil moisture pattern. We start in section 2 with a diagnostic analysis of AGCM simulations. This analysis provides the information needed to design specialty simulations (section 3 ) that confirm the operation of the mechanism within the model. Supporting evidence that the mechanism operates in nature as well - i.e., evidence that it is not simply a model construct - is extracted from reanalysis data in section 4 .

\section{Analysis of Atmospheric Model Simulations}

The modeling system utilized throughout this study is the GEOS-5 system of the National Aeronautics and Space Administration Global Modeling and Assimilation Office (NASA/GMAO). All simulations examined use only the coupled atmospheric and land model components of the system, prescribing sea surface temperatures (SSTs) from observations using AMIP-style (Atmospheric Model Intercomparison Study; Gates et al. 1992) protocols. The atmospheric model is described in some detail by Rienecker et al. (2008) and Molod et al. (2012), and the land surface model is the Catchment model of Koster et al. (2000).

The present section focuses on the analysis of an archived ensemble of ten simulations covering the period 1871-2011 [Schubert et al. 2014]. Monthly data from these simulations are available at a resolution of $1.25^{\circ} \times 1^{\circ}$. We focus here on monthly averages of root zone soil moisture (WRZ), 2-meter air temperature (T2M), and meridional wind velocity at $250 \mathrm{mb}$ (V250) taken from the last 35 years of each simulation. Focusing on this latter period, which still provides a full 350 years of data for analysis, allows for more consistency with the MERRA 
reanalysis period (section 4) and, more importantly, reduces the impact of the long-term temperature trend on our results.

For convenience, the monthly data were aggregated to a resolution of $2.5^{\circ} \times 2^{\circ}$. Soil moisture values were then converted to standard normal deviates:

$$
Z_{\mathrm{WRZ}}(\mathrm{i}, \mathrm{j}, \mathrm{m}, \mathrm{n})=\left[\mathrm{WRZ}(\mathrm{i}, \mathrm{j}, \mathrm{m}, \mathrm{n})-\mathrm{M}_{\mathrm{WRZ}}(\mathrm{i}, \mathrm{j}, \mathrm{m})\right] / \sigma_{\mathrm{WRZ}}(\mathrm{i}, \mathrm{j}, \mathrm{m}),
$$

where $i$ and $j$ are the longitudinal and latitudinal indices of the grid cell, $m$ is the month, $n$ is the year, $\mathrm{M}_{\mathrm{WRZ}}$ is mean of WRZ over all years, and $\sigma_{\mathrm{WRZ}}$ is its standard deviation. The T2M and V250 data were converted to simple anomalies:

$$
\begin{aligned}
& \mathrm{T} 2 \mathrm{M}(\mathrm{i}, \mathrm{j}, \mathrm{m}, \mathrm{n})^{\prime}=\mathrm{T} 2 \mathrm{M}(\mathrm{i}, \mathrm{j}, \mathrm{m}, \mathrm{n})-\mathrm{M}_{\mathrm{T} 2 \mathrm{M}}(\mathrm{i}, \mathrm{j}, \mathrm{m}) \text {, and } \\
& \mathrm{V} 250(\mathrm{i}, \mathrm{j}, \mathrm{m}, \mathrm{n})^{\prime}=\mathrm{V} 250(\mathrm{i}, \mathrm{j}, \mathrm{m}, \mathrm{n})-\mathrm{M}_{\mathrm{V} 250}(\mathrm{i}, \mathrm{j}, \mathrm{m})
\end{aligned}
$$

Our analysis focused on identifying the April soil moisture pattern over CONUS (the conterminous United States) that is most strongly related to July temperature anomalies in the U.S. Great Plains and thus may someday (with more research) be useful for prediction. To simplify and thereby clarify the analysis, we searched for what is arguably the simplest 2-D soil moisture pattern possible: a "dipole" of soil moisture anomalies, with a positive anomaly in one location paired with a negative anomaly in another. The search proceeded as follows. For a given pairing of grid cells (representing the dipole centers), the 350 Aprils were ranked in terms of dipole strength:

$$
\begin{array}{rlrl}
\text { dipole strength } & =-\mathrm{D}_{1}(\mathrm{n}) \mathrm{D}_{2}(\mathrm{n}) & & \text { if } \mathrm{D}_{1}(\mathrm{n})>0 \\
& =\quad 0 \quad & \text { if } \mathrm{D}_{1}(\mathrm{n})<0,
\end{array}
$$


where $D_{1}(n)$ is the average value of $Z_{W R Z}$ in April of year $n$ in the 9 grid cells centered on the first chosen dipole point (so as to consider a spatial scale of $\sim 600 \mathrm{~km}$ ) and $\mathrm{D}_{2}(\mathrm{n})$ is the corresponding average for the 9 grid cells centered on the second point. The subset of simulated Aprils with dipole strengths in the top $20 \%$ of all values ( 70 Aprils in all) comprised a composite of years over which the subsequent July T2M spatial fields were averaged. This process was repeated with both orderings of every possible pairing of grid cells in CONUS, and the particular dipole that produced the highest composited July T2M anomaly in the Great Plains was identified.

Results are shown in Figure 1. Figure 1a shows the April $Z_{\mathrm{WRZ}}$ field for the composited years for the identified dipole, with the centers of this dipole marked as white circles. The associated July T2M' composite for that subset of years is shown in Figure 1b. According to the GCM, when April soil moisture is high in the northwestern U.S. and low in the Great Plains, the subsequent July temperature anomaly in the Great Plains tends to be positive, by more than $2^{\circ} \mathrm{K}$ in some places. Supplemental composites using the same sampling of years but different ensemble members do not show the same signal; the July temperature signal shown is not explained by the particular SSTs of the composited years.

The dipole pattern in Figure 1a and its impact on Great Plains temperature is the main finding of this part of the analysis, and yet two additional points are worth making. First, an analogous compositing based on a monopole of April soil moisture (not shown) does not lead to such large temperature anomalies; the dipole provides the larger temperature signal. Second, the composited July V250 anomaly field (Figure 1c) shows a distinct wave pattern, with a positive lobe of V250 anomalies in the western half of the continent and a negative lobe in the eastern half. Together these findings motivate the GCM experiments discussed in the next section. 


\section{Focused Experiments}

\section{a. Experiment 1: The Land-Atmosphere Component of the Feedback Loop}

To examine how land conditions may affect dynamical patterns in the atmosphere, we compare two ensembles of GEOS-5 simulations covering April-July of 2012. The control ensemble consists of 192 AMIP-style simulations performed on a $1^{\circ} \times 1^{\circ}$ grid, the simulations differing from each other in their atmospheric initial conditions, taken from different years of the MERRA reanalysis (with slight perturbations imposed in each year to increase the ensemble size). The experiment ensemble is identical to the control except for the imposition of a soil moisture dipole pattern: during April in these simulations, any precipitation simulated over a northwestern region of the U.S. (the blue box in Figure 2a) was artificially increased five-fold before being applied to the land surface (with the increase deposited as liquid), and precipitation simulated over the Great Plains (the red box in Figure 2a) was zeroed. Precipitation was not modified during the May-July period. 
Shown in Figure 2b,c are the resulting differences in key July fields (experiment minus control). The precipitation modifications led to soil moisture anomalies that extended into July, which in turn induced strong July temperature anomalies, including a heating in the U.S. Great Plains (Figure 2b). The imposed soil moisture dipole also had an impact on the atmosphere's general circulation, as manifested in the V250 winds - Figure 2c shows a wavelike pattern in the V250 difference field, similar to that seen in Figure 1c. Indeed, the source of this pattern can only be the imposed dipole, as all other aspects of the two ensembles are identical.

Two additional points are worth making about this phase of the analysis. First, the wavelike pattern does not appear until June (not shown) and July, which is consistent with the idea that soil moisture fields influence the atmosphere the most during the warmest months, when evaporation is highest. Second, we performed two supplemental 192-member ensembles (results not shown), one that imposed only the April wetting in the northwestern U.S., and one that imposed only the April drying in the Great Plains. Both ensembles show some warming over the Great Plains. Although the warm anomaly in the latter is much higher, it is still lower than that in Figure $2 b$ - again, the dipole pattern produces a greater warm anomaly than the monopole pattern.

\section{b. Experiment 2: The Atmosphere-Land Component of the Feedback Loop}

The other phase of the feedback loop, i.e., the ability of a specific wavelike structure to induce surface warming in the Great Plains, is examined here with two additional sets of ensembles. The control for this comparison is an AMIP-style 32-member ensemble covering the period May 21 - July 31, 2012. The experiment is a 32-member ensemble differing from the 
control in only one way: upstream of North America, within the box outlined in Figure 3a, atmospheric conditions were forced to agree with conditions captured by the MERRA reanalysis for the period, using a technique called "replay". The motivation for this modification was the known existence of a Rossby-wave pattern over North America during the hot summer of 2012 (Wang et al. 2014) and the expectation that the wave was instigated by conditions somewhere in this upstream area (e.g., Schubert et al. 2011). The hope was that with these upstream conditions prescribed, the V250 wave patterns seen in Figures 1c and 2c would be more prevalent in the experiment ensemble than in the control ensemble.

This turns out to be the case, especially in June. Figure 3c shows the difference between the average June V250 fields from the experiment and control ensembles. A clear wavelike pattern is seen, with a positive lobe in the west and a negative lobe in the east. Furthermore, surface warming appears in the central U.S. (Figure 3b).

Given the experimental design, this warming is a direct consequence of the upstream forcing, presumably through the generation of planetary waves; the warming appears roughly between the positive and negative lobes of the V250 difference field, i.e., at the location of an increase in the upper level high where: (i) subsidence tends to induce cloudless skies and thus increased surface radiative forcing, and (ii) surface winds tend to advect warm air in from the

\footnotetext{
${ }^{1}$ The GEOS-5 Data Assimilation system was developed so that analysis increments produced during the assimilation cycle are inserted gradually, typically over a 6-hr interval (Bloom et al. 1996). This approach has been generalized so that the model can be "replayed" against an existing analysis (e.g., MERRA), i.e., the analysis increments can be used to guide the evolution of model state in an (otherwise) free-running AGCM toward that of the analysis. This approach has been further generalized so that only certain regions of the atmosphere are constrained to agree with the analysis; this is the approach used here.
} 
south. Schubert et al. (2011) found that at monthly time scales, such waves are indeed well correlated with continental surface temperatures during summer, with correlation patterns that are consistent with the waves' largely barotropic structure, with a slight westward tilt with height.

\section{Supporting Evidence from Reanalysis}

It is natural to ask if this mechanism - a soil moisture dipole inducing a planetary wave pattern, which can in turn amplify Great Plains warming - also operates in nature. Because nature does not allow the type of experiments performed in sections 2 and 3, demonstrating this conclusively is impossible. Supporting evidence for the feedback is nevertheless found in MERRA reanalysis data (Rienecker et al. 2011). Focusing on monthly averages, we processed the 35 April root zone soil moisture fields in this dataset (covering 1979-2013) into standard normal deviates and converted the 35 July temperature and V250 fields into anomalies. We then identified the 7 Aprils ( $20 \%$ of the total) with the highest soil moisture dipole strength, where dipole strength is defined as in (4), averaging over the boxes shown in Figure 2a.

Figure 4a shows the average April root zone soil moisture field for the 7-yr composite; the dipole is, by construct, apparent in the plot. Figure $4 \mathrm{~b}$ shows the July T2M anomaly field. Warm July conditions, with an average anomaly of up to $1 \mathrm{~K}$ or more, are seen in the Great Plains for the subsetted years - the historical anomalies were arguably predictable from the presence of the April soil moisture dipole. Furthermore, the composite July V250 anomaly field for these years shows a pattern very similar to that seen in Figures 1c and 2c, supporting the idea that the soil moisture dipole had an impact on the planetary wave structure. 
MERRA reanalysis data, while not conclusive, are thus consistent with the feedback mechanism established for the AGCM. Of course, reanalysis data are not pure observations; model machinery is reflected to some extent in the data, and indeed the AGCM underlying MERRA is an updated version of that used in Sections 2 and 3. Nevertheless, the number of observations assimilated into the reanalysis over North America gives us confidence that the July T2M and V250 fields, and even the April WRZ anomalies, in the MERRA dataset are realistic, reflecting what actually happened.

\section{Summary}

Figure 2 shows that in the AGCM, imposing a dipole structure in April soil moisture, with wet conditions in the northwestern U.S. and dry conditions in the Great Plains, promotes a July wave pattern in the atmosphere. Figure 3 shows that instigating such a wave pattern (in this case through a remote mechanism, over Asia) leads to increased $2 \mathrm{~m}$ air temperatures in the U.S. Great Plains and, to a small extent, cooler temperatures over the Northwest, bolstering the surface temperature signal. While much of the Great Plains temperature anomaly in Figure $2 b$ is presumably a reflection of drier soil moistures there and the associated decrease in evaporative cooling, not all of it is; the induced formation of the wave structure and its ability to feed back on the temperature anomaly constitutes a feedback loop for the model climate, one involving a change in the large-scale circulation. Evidence for the mechanism is seen in the MERRA reanalysis (Figure 4). 
The dipole identified and utilized in our experiments is, of course, only one of potentially 224 many soil moisture patterns of relevance to land-atmosphere feedback in the climate system.

225 The approach presented here could prove useful in identifying and analyzing additional patterns.

227 Acknowledgements: Support for this project was provided by the NOAA Modeling, Analysis, 228 Predictions and Projections (MAPP) program, the NASA Energy and Water cycle Study

229 (NEWS) program, and the NASA Modeling, Analysis, and Prediction Program. 
231

232

Betts, A.K., J.H. Ball, A.C.M. Beljaars, M.J. Miller, and P. Viterbo, 1994: Coupling between land-surface, boundary-layer parameterizations and rainfall on local and regional scales: Lessons from the wet summer of 1993. Preprints, Fifth Conf. on Global Change Studies, 74th Annual Meeting, Nashville, TN, Amer. Meteor. Soc.

Betts, A. K., and J. H. Ball, 1995: The FIFE surface diurnal cycle climate. J. Geophys. Res., $100,25679-25693$.

Bloom, S., L. Takacs, A. DaSilva, and D. Ledvina, 1996: Data assimilation using incremental analysis updates. Mon. Wea. Rev., 124, 1256-1271.

Delworth, T.L., and S. Manabe, 1989: The influence of soil wetness on near-surface atmospheric variability. J. Clim., 2, 1447-1462.

Douville, H., F. Chauvin, and H. Broqua, 2001: Influence of soil moisture on the Asian and African monsoons, Part 1, Mean monsoon and daily precipitation. J. Clim., 14, 23812403.

Findell, K. L., and E. A. B. Eltahir, 1997: An analysis of the soil moisture-rainfall feedback, based on direct observations from Illinois. Water Resour. Res., 33, 725-735.

Gates, W. L., 1992: AMIP: The Atmospheric Model Intercomparison Project. Bull. Amer. Meteor. Soc., 73, 1962-1970.

Guo, ZC, P. A. Dirmeyer, T. DelSole, and R. D. Koster, 2012: Rebound in atmospheric predictability and the role of the land surface. J. Climate, 25, 4744-4749. 
Koster, R. D., M. J. Suarez, and M. Heiser, 2000: Variance and predictability of precipitation at seasonal-to-interannual timescales. J. Hydrometeor., 1, 26-46.

Koster, R. D., M. J. Suarez, A. Ducharne, M. Stieglitz, and P. Kumar, 2000: A catchment-based approach to modeling land surface processes in a general circulation model: 1. Model structure, J. Geophys. Res., 105(20), 24,809-24,822.

Koster, R. D., M. J. Suarez, R. W. Higgins, and H. M. Van den Dool, 2003: Observational evidence that soil moisture variations affect precipitation. Geophys. Res. Lett., 30, doi:10.1029/2002GL016571.

Koster, R. D., M. J. Suarez, and M. Heiser, 2000: Variance and predictability of precipitation at seasonal-to-interannual timescales. J. Hydrometeor., 1, 26-46.

Koster, R. D., and Co-Authors, 2011: The second phase of the Global Land-Atmosphere Coupling Experiment, Soil moisture contributions to subseasonal forecast skill. J. Hydromet., 12, 805-822.

Molod, A., L. Takacs, M. Suarez, J. Bacmeister, I.-S. Song, and A. Eichmann, 2012: The GEOS5 Atmospheric General Circulation Model: Mean Climate and Development from MERRA to Fortuna. NASA Technical Report Series on Global Modeling and Data Assimilation, NASA TM-2012-104606, Vol. 28, 117 pp

Rienecker, M. M., and Coauthors, 2008: The GEOS-5 Data Assimilation System Documentation of versions 5.0.1 and 5.1.0, and 5.2.0. NASA Tech. Rep. Series on Global Modeling and Data Assimilation, NASA/TM-2008-104606, Vol. 27, 92 pp. 
Rienecker, M. M., and Co-Authors, 2011: MERRA, NASA's Modern-Era Retrospective Analysis for Research and Applications. J. Climate, 24, 3624-3648.

Shukla, J., and Y. Mintz, 1982: Influence of land-surface evapotranspiration on the earth's climate. Science, 215, 1498-1501.

Schubert, S., H. Wang, and M. Suarez, 2011: Warm Season Subseasonal Variability and Climate Extremes in the Northern Hemisphere: The Role of Stationary Rossby Waves. J. Climate, 24, 4773-4792.

Schubert, S., H. Wang, R. Koster, M. Suarez, and P. Groisman, 2014: Northern Eurasian Heat Waves and Droughts. J. Climate, 27, 3169-320.

Seneviratne, S. I., and Co-Authors, 2010: Investigating soil moisture-climate interactions in a changing climate, A review. Earth-Sci. Rev., 99, 125-161.

Taylor, C. T., A. Gounou, F. Guichard, P. P. Harris, R. J. Ellis, F. Couvreux, and M. De Kauwe, 2011: Frequency of Sahelian storm initiation enhanced over mesoscale soil-moisture patterns. Nature Geosci., 4, 430-433.

van den Dool, H., J. Huang, and Y. Fan, 2003: Performance and analysis of the constructed analogue method applied to U.S. soil moisture over 1981-2001. J. Geophys. Res., 108, 10.1029/2002JD003114.

Wang, H., S. Schubert, R. Koster, Y.-G. Ham, and M. Suarez, 2014: On the Role of SST Forcing in the 2011 and 2012 Extreme U.S. Heat and Drought: A Study in Contrasts. J. Hydromet., in press. 
291

292

293

294

295

Figure 1. a. Composite of the standard normal deviate of April soil moisture over the $20 \%$ of simulation years for which the April soil moisture dipole centered on the small white circles is strongest (see text). b. Corresponding composite (i.e., for the same simulation years) of July surface air temperature anomalies. c. Corresponding composite (i.e., for the same simulations years) of July $250 \mathrm{mb}$ meridional wind anomalies.

Figure 2. a. Locations where April precipitation is modified in specialized experiments. April precipitation water applied to the land surface is increased five-fold in the blue area, and it is set to zero in the red area. b. Resulting July surface air temperature anomalies. c. Resulting July $250 \mathrm{mb}$ meridional wind anomalies.

Figure 3. a. Location of the upstream area over which atmospheric states were forced to agree with states from an analysis (and thus were forced to be realistic), using a technique known as 'replay'. b. Resulting June surface air temperature anomalies. c. Resulting June $250 \mathrm{mb}$ meridional wind anomalies.

Figure 4. a. Standard normal deviate of reanalysis April soil moisture, composited over the $20 \%$ of reanalysis years for which the April soil moisture dipole in the outlined areas (same as those in Figure 2a) is strongest (see text). b. Corresponding composite (i.e., for the same reanalysis years) of July surface air temperature anomalies. c. Corresponding composite (i.e., for the same reanalysis years) of July $250 \mathrm{mb}$ meridional wind anomalies. 

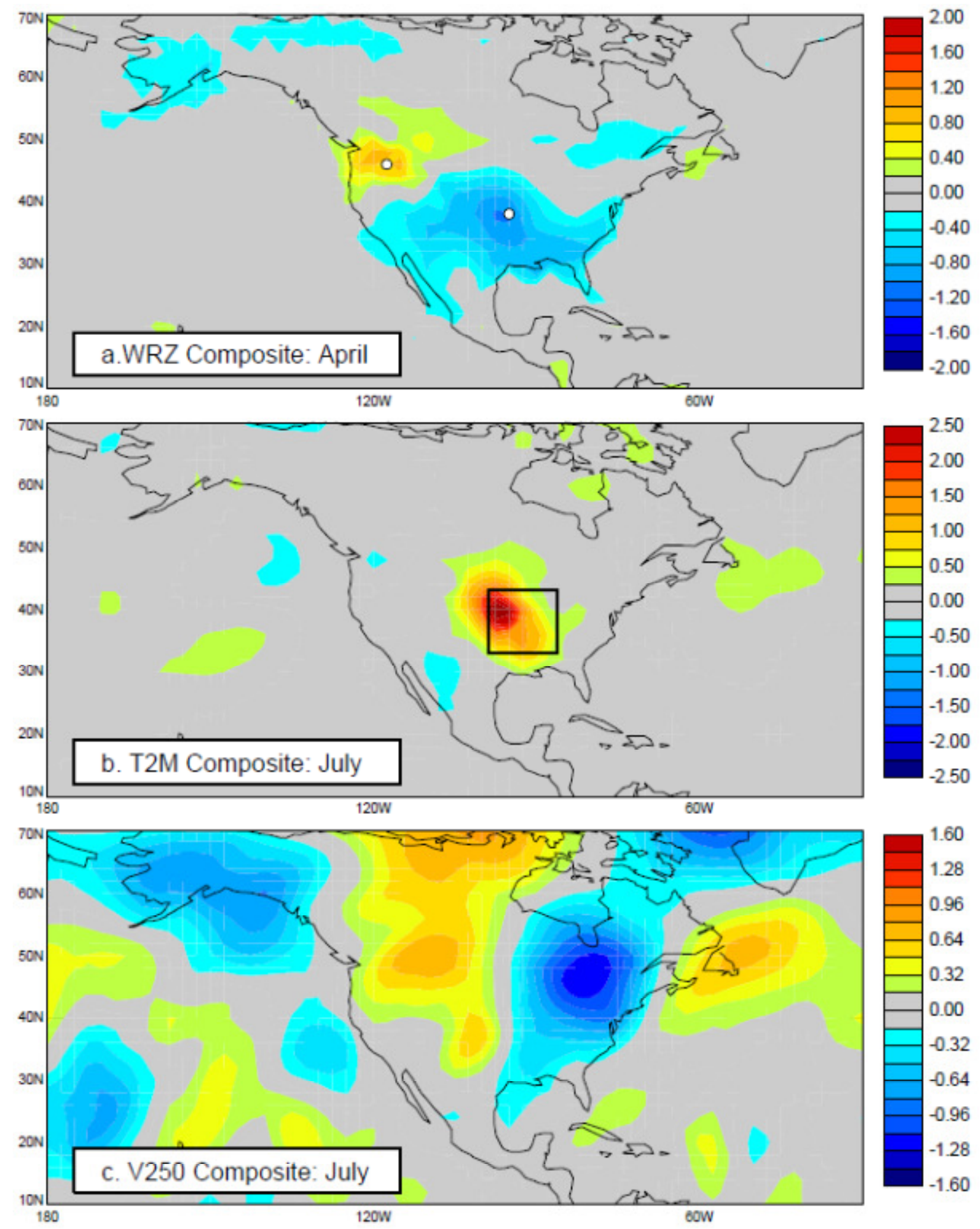

Figure 1. a. Composite of the standard normal deviate of April soil moisture over the $20 \%$ of simulation years for which the April soil moisture dipole centered on the small white circles is strongest (see text). b. Corresponding composite (i.e., for the same simulation years) of July surface air temperature anomalies. c. Corresponding composite (i.e., for the same simulations years) of July $250 \mathrm{mb}$ meridional wind anomalies. 


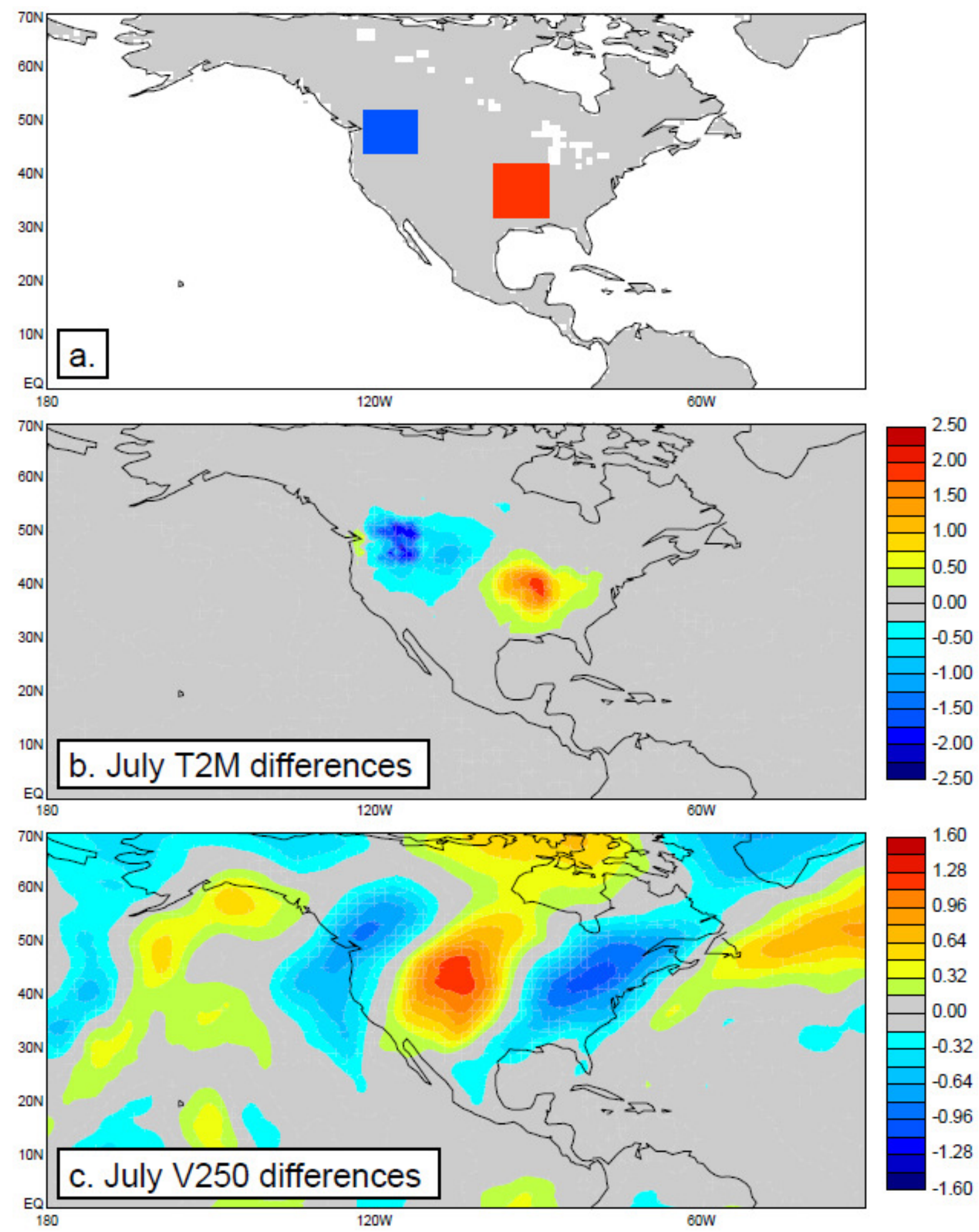

Figure 2. a. Locations where April precipitation is modified in specialized experiments. April precipitation water applied to the land surface is increased five-fold in the blue area, and it is set to zero in the red area. b. Resulting July surface air temperature anomalies. c. Resulting July $250 \mathrm{mb}$ meridional wind anomalies. 

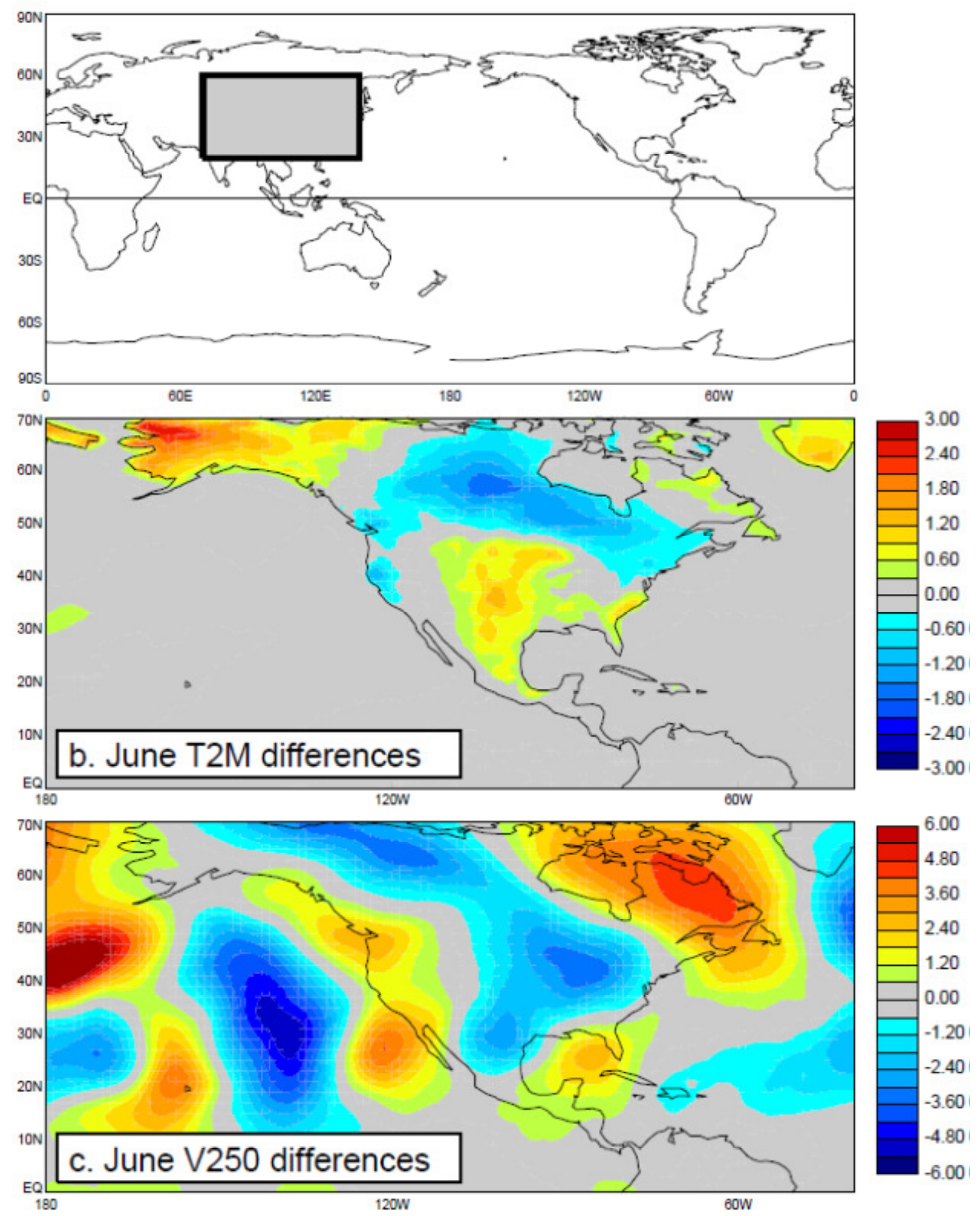

Figure 3. a. Location of the upstream area over which atmospheric states were forced to agree with states from an analysis (and thus were forced to be realistic), using a technique known as 'replay'. b. Resulting June surface air temperature anomalies. c. Resulting June $250 \mathrm{mb}$ meridional wind anomalies. 


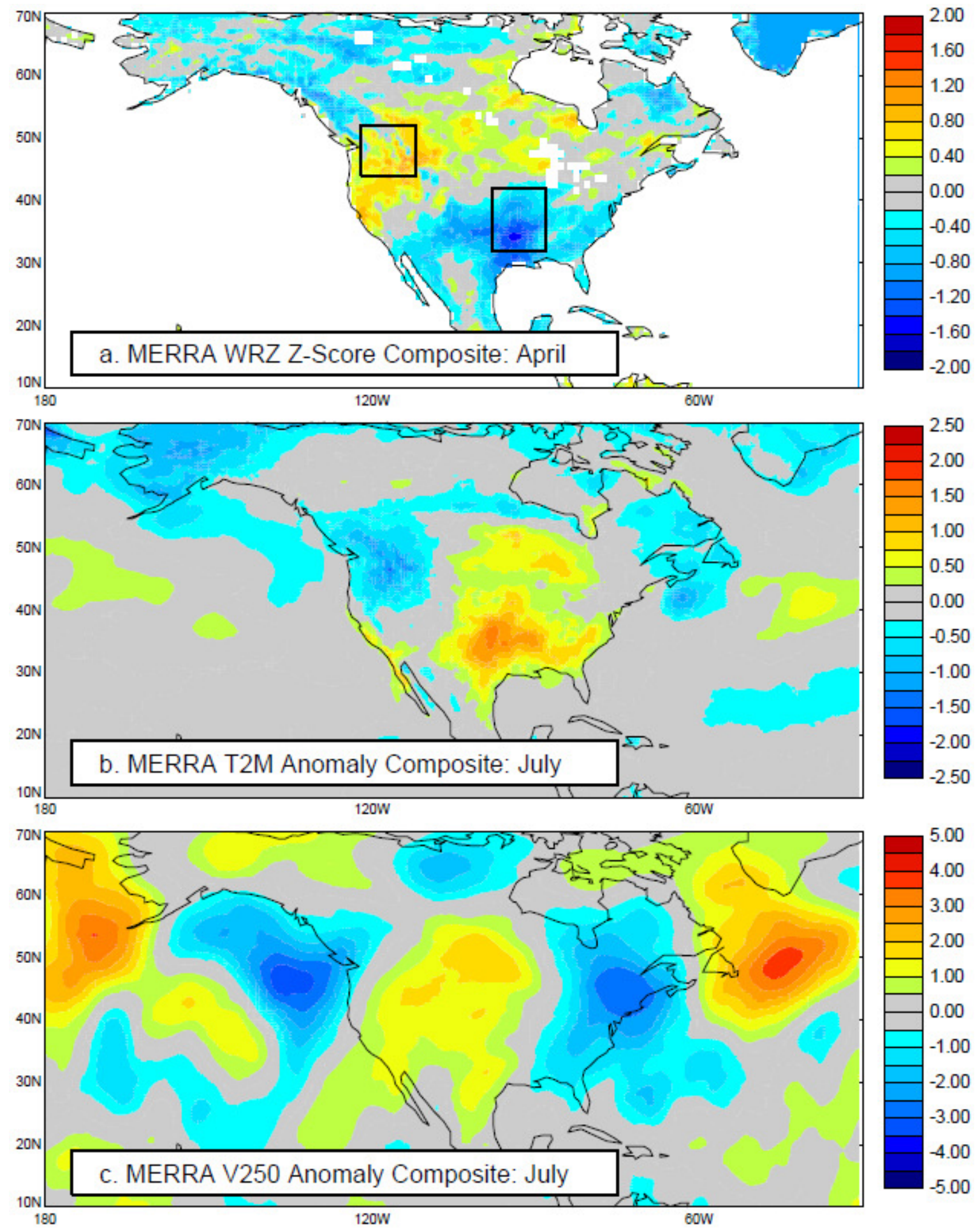

Figure 4. a. Standard normal deviate of reanalysis April soil moisture, composited over the $20 \%$ of reanalysis years for which the April soil moisture dipole in the outlined areas (same as those in Figure 2a) is strongest (see text). b. Corresponding composite (i.e., for the same reanalysis years) of July surface air temperature anomalies. c. Corresponding composite (i.e., for the same reanalysis years) of July $250 \mathrm{mb}$ meridional wind anomalies. 